\title{
DENSIDADE E FORÇA DE EMPUXO: IMAGINAÇÃO E PRODUÇÃO DE UM RECURSO DIDÁTICO
}

\author{
DENSITY AND BUOYANCY: IMAGINATION AND PRODUCTION OF A \\ DIDACTIC RESOURCE
}

Andrela Garibaldi Loureiro Parente ${ }^{1}$

ORCID iD: 0000-0003-3396-700X

José Moysés Alves ${ }^{2}$

ORCID iD: 0000-0003-1307-1249

Sérgio Henrique de Oliveira Bezerra ${ }^{3}$

DRCID iD: 0000-0002-7636-4439

\section{RESUMO}

Neste artigo, apresentamos uma pesquisa (auto)formativa biográfica sobre o papel da imaginação na atividade de uma professora, durante a produção de um recurso didático, para ensinar os conceitos de densidade e força de empuxo. A partir do texto de campo, descrevendo a motivação inicial e o processo de criação, realizamos o processo analítico-interpretativo, inspirados na pesquisa narrativa, para elaborar a biografia do percurso de produção do recurso. A biografia contém a interpretação do processo por meio da explicitação dos princípios orientadores do percurso de produção do recurso didático. Concluímos que a produção do recurso e, especialmente, a reflexão sobre o processo de sua produção, são momentos de aprendizagem e de formação para o professor, pelas possibilidades de teorizar sobre os problemas, equacioná-los e propor-lhes soluções práticas. Essa narrativa tem potencial de contribuir com a área de educação em ciências, inspirando a criação de novos materiais didáticos, de outras pesquisas sobre os percursos de produção, fortalecendo espaços de compartilhamento de biografias de professores que valorizam a personalização do ensino.

Palavras-chave: Imaginação. Recurso Didático. Ensino de Ciências.

\begin{abstract}
1- Doutora em Educação para a Ciência, Universidade Estadual Paulista (UNESP - Campus Bauru) - Professora Adjunta IV - Universidade Federal do Pará (UFPA), Belém, Pará, Brasil. Endereço para correspondência: Avenida Perimetral, 7, Residencial Jardim Universitário, Quadra 2, Casa 8, Guamá, Belém, Pará, Brasil, CEP: 66075-750, E-mail: andrela@ufpa.br.

2- Doutor em Psicologia, Universidade de São Paulo (USP) Professor Titular - Universidade Federal do Pará (UFPA), Belém, Pará, Brasil. Endereço para correspondência: Travessa dos Tupinambás, 540/1204, Jurunas, Belém, Pará, Brasil, CEP: 660333-815, E-mail: jmalves@ufpa.br.

3- Mestre em Ensino de Física, Universidade Federal do Pará (UFPA/MNPEF) - Discente do Programa de PósGraduação em Educação em Ciências e Matemáticas (IEMCI/UFPA), Belém, Pará, Brasil. Endereço para correspondência: Avenida Hélio Gueiros, nº 37, Cond. Ilhas do Atlântico, Bloco Comandatuba, Ap. 103, Coqueiro, Ananindeua, Pará, Brasil, CEP: 67120-370, E-mail: sergiohobezerra@yahoo.com.br.
\end{abstract}


In this article, we present a biographical (auto) formative research on the role of imagination in the activity of a teacher, during the production of a didactic resource, to teach the concepts of density and buoyancy. From the field text, describing the initial motivation and the creation process, we carried out the analytical-interpretive process, inspired by narrative research, to elaborate the biography of the resource's production path. The biography contains the interpretation of the process by explaining the guiding principles of the production path of the didactic resource. We conclude that the production of the resource and, especially, the reflection on the process of its production, are moments of learning and training for the teacher, due to the possibilities of theorizing about the problems, solving them and proposing practical solutions to them. This narrative has the potential to contribute to the area of science education, inspiring the creation of new teaching materials, other research on the production pathways and strengthening spaces for sharing teachers' biographies, which value the personalization of teaching.

Keywords: Imagination. Didactic Resource. Science Teaching.

\section{INTRODUÇÃO}

Interessados em contribuir para uma Educação em Ciências diferenciada e de qualidade, que promova a personalização das experiências pelos estudantes e favoreça o seu protagonismo, comprometemo-nos, colaborativamente, com nosso processo formativo. Neste artigo, relatamos uma pesquisa (auto)formativa biográfica do percurso de produção de um recurso didático, elaborado pela primeira autora. Por essa razão, daqui em diante, optamos por escrevêlo na primeira pessoa do singular. Retomaremos a primeira pessoa do plural nas considerações finais.

O professor lida com a complexidade do processo de aprendizagem e pode propor alternativas para abordar os problemas que se originam no transcurso de sua prática pedagógica. Entre tais alternativas, destaco a produção de recursos didáticos, aqui tratados como materiais instrucionais auxiliares à atividade do professor, que poderão atuar como elementos de apoio para determinadas abordagens metodológicas e contribuir para a aprendizagem.

Contudo, compreendo que o processo de criação de tais recursos nem sempre é compartilhado e, por essa razão, perde-se a possibilidade de explorar a dimensão formadora da experiência vivida. Neste artigo, dedico-me a refletir a criação de um experimento investigativo para ensinar densidade e força de empuxo. A partir da perspectiva analítico-interpretativa, pesquiso sobre o papel da imaginação no percurso biográfico de produção deste experimento didático.

Em geral, a imaginação esteve mais relacionada à arte do que à ciência (GURGEL; PIETROCOLA, 2011), mais à educação infantil do que à educação básica e superior, sendo pouco explorada no ensino dos conteúdos escolares (MITJÁNS MARTÍNEZ, 2014a). A imaginação é uma característica do ensino criativo, sendo esse cada vez mais urgente, devido à 
necessidade de os professores gerenciarem seu próprio trabalho e realizarem-se pessoal e profissionalmente (WOODS, 1991).

Pietrocola (2004, p.132) compartilhou sua experiência pessoal, ao refletir sobre a importância de incentivar o interesse e a curiosidade dos estudantes pela ciência. Ele afirmou que "[...] a ciência é a capacidade de exercitar nossa imaginação e criatividade e atingir nossas emoções por meio dos desafios ao intelecto”. González Rey (2014, p. 44) vai ainda mais longe, quando afirma que a imaginação "representa a única forma possível para gerar inteligibilidade sobre os significados que criamos para dirigir nossas práticas neste mundo".

Entretanto, a imaginação é, comumente, desconsiderada na aprendizagem dos conteúdos escolares (MITJÁNS MARTÍNEZ; 2014a). Isso não é diferente em relação ao ensino de ciências, como afirmaram Gurgel e Pietrocola (2011, p. 1602-12), “o imaginário dos alunos é pouco explorado quando conduzimos nossas aulas em classes de ciências”.

Para Mitjáns Martínez (2014a), dois fatores contribuem para a pouca importância atribuída à imaginação na aprendizagem escolar: a concepção de ensino-aprendizagem e a concepção de conhecimento. A aprendizagem tem sido concebida como um modelo de transmissão-recepção, no qual o intelecto é representado por um sistema de informação cognitiva-intelectual. Essa representação de aprendizagem como armazenamento de informações factuais é inadequada para criar pensadores (EGAN, 2007). Sobre a concepção de conhecimento, tem prevalecido a compreensão superada de ciência como um processo acabado e a-histórico.

Mudanças nas representações de aprendizagem no espaço escolar são possíveis e desejáveis (WOODS, 1991), sendo uma das possibilidades trabalhar com os professores a utilização de estratégias diferentes, na formação inicial e continuada, como recomenda Mitjáns Martínez (2014a, p. 86), ao indicar a necessidade de:

[...] Gerar espaços coletivos de reflexão vivencial que favoreçam a conscientização de seus próprios processos imaginativos, a vivência e o jogo com a imaginação pelos próprios professores e a experimentação de estratégias diversas para a sua incentivação e utilização no processo de ensino

Para mim, pesquisar, colaborativamente, o processo de criação de um recurso didático é criar "espaços coletivos de reflexão vivencial” (MITJÁNS MARTÍNEZ, 2014a), na direção de problematizar o papel da imaginação na atividade do professor. Tal investigação me permite tomar consciência de meus processos imaginativos, na medida em que gero conhecimento sobre um modo de tornar ensinável conteúdos de ensino de ciências, na formação inicial de 
professores para atuar nos anos iniciais.

Neste artigo, apresento, inicialmente, o referencial teórico sobre o professor investigador e sua imaginação, na produção de recursos didáticos. Em seguida, caracterizo a pesquisa (auto)formativa biográfica, que inspira o presente estudo. Depois, apresento a análise dos textos de campo, explicitando os orientadores da produção do recurso didático. Ao fazê-lo, discuto os conceitos de densidade e força de empuxo. Nas considerações finais, reflito sobre a dimensão formadora da experiência vivida, indicando contribuições para a área de educação em ciências.

\section{REFERÊNCIAL TEÓRICO}

Estudos sobre a prática pedagógica e a formação de professores têm confirmado a importância de o professor tornar-se pesquisador de sua prática (CUNHA, 1996; LÜDKE et al. 2001; ANDRÉ, 2016; GATTI et al. 2019; ALVES; PARENTE, 2020; PARENTE; ALVES, 2020). Stenhouse (1987) definiu o termo professor investigador em oposição à ideia de um professor especialista técnico. Reconheceu a qualidade inovadora da atividade profissional, quando orientada à construção de uma prática propiciadora de maior interesse e envolvimento dos estudantes, tratando de forma relevante os conteúdos de ensino, mas também orientada para atender às necessidades dos estudantes (FAGUNDES, 2016).

Sthenhouse (1987) compreendeu que as situações de ensino "refletem características únicas e singulares" e dependem das "intenções e das significações atribuídas por seus protagonistas" (CONTRERAS, 2002, p.115). Para ele, ao mesmo tempo que o professor cria soluções, também desenvolve o seu trabalho melhor, porque constrói um repertório de conhecimentos que o ajuda a lidar com situações novas. Nesse sentido, considerava o ensino uma arte, pois expressava a busca pelo desenvolvimento de valores que se realizavam na prática pedagógica.

A produção de um recurso de ensino está em consonância com essa intenção de criar condições que propiciem o desenvolvimento de valores, embora não possa assegurá-lo. Outras condições precisam ser consideradas quando não pensamos a aprendizagem como um reflexo direto do ensino (MITJÁNS MARTÍNEZ, 2006), mas como fenômeno complexo e diverso, que depende "tanto do objeto do conhecimento e das características da relação pedagógica, quanto dos níveis de desenvolvimento e características do próprio aprendiz" (TUNES; TACCA; MITJÁNS MARTÍNEZ, 2006, p.118-119).

Produzir um recurso didático, como dito anteriormente, situa o professor em um 
movimento próprio de formação, dentre outras possibilidades de construção de conhecimento sobre o conteúdo do ensino, gerando uma forma própria de ensinar. A teoria tem um papel fundamental nesse desenvolvimento, não como um modelo a ser seguindo, mas "garantindo o exercício contínuo do olhar e a busca pela compreensão, sem os quais depositaríamos permanentemente nossas dúvidas na primeira certeza que nos parecesse a única" (LACERDA (2002, p. 84).

Toda produção envolve imaginação, uma capacidade humana culturalmente desenvolvida que se manifesta "igualmente em todos os aspectos da vida cultural, possibilitando a criação artística, científica e tecnológica" (VYGOTSKY, 2014, p. 4). Mas, como argumenta González Rey (2014), a imaginação foi pouco valorizada no âmbito da pesquisa e da prática profissional, tanto no âmbito da psicologia quanto da educação. Em particular, porque as teorias de aprendizagem desenvolvidas, no final do século XIX e primeira metade do século XX, sustentaram "visões teóricas de forte cunho naturalista e que procuraram explicar a aprendizagem de um modo reducionista" (TUNES; TACCA; MITJÁNS MARTÍNEZ, 2006, p. 126), negando o sujeito da aprendizagem e sua dimensão subjetiva (GONZÁLEZ REY, 2008).

Para González Rey (2014, p. 41), a imaginação não guarda relação direta com a realidade, mas com os significados produzidos pelo homem, em um processo de integração de modelos subjetivos. É uma produção autogerada, já que "as coisas na experiência humana só existem através do sentido que elas cumprem na própria experiência, e não por aquilo que possam representar fora dessa experiência”.

Entendo que a capacidade de criar recursos didáticos está relacionada com a compreensão teórica da prática pedagógica valorizada pelo professor. Não depende apenas da disponibilidade de instrumentos ou aparatos de ensino. Para Woods (1991), o processo de criação inclui um período de incubação das ideias, dos recursos, o respeito à criatividade e o seu encorajamento, além do apoio à cultura do estudante.

O processo de criação depende de condições simbólico-emocionais, favorecedoras de processos criativos, nas quais o professor se assume como sujeito (GONZÁLEZ REY; 2014). Desse modo, a capacidade de criar depende das experiências, das intenções e dos desejos do homem (VYGOTSKY, 2014). Não é uma atividade fortuita. Nesse sentido, situo a motivação para a criação do recurso didático aqui discutido nos significados produzidos por mim diante da necessidade de ensinar aos licenciandos, do curso de Licenciatura em Ciências, Matemática e Linguagens (LICML), da Universidade Federal do Pará (UFPA), os conceitos de densidade, força de empuxo e as diferenças entre ambos. 
Pesquisar o processo de criação do recurso didático e nele compreender o papel da imaginação gera aprendizagens, em uma perspectiva (auto)formativa, na qual a aprendizagem do adulto implica sua condição de "ator e investigador, criando as condições para que a formação se faça na produção do saber e não, como até agora, no seu consumo" (NÓVOA, 2010, p. 168). Nesse sentido, atividade profissional e pesquisa se articulam gerando desenvolvimento.

\section{METODOLOGIA: A INVESTIGAÇÃO SOBRE O PERCURSO DE PRODUÇÃO DO RECURSO DIDÁTICO}

Iniciei o percurso de produção do recurso didático, no ano de 2013, com a intenção de contribuir para o processo de aprendizagem dos licenciandos. Também com o desejo de dispor de um recurso auxiliar no ensino das noções de densidade e força de empuxo. $\mathrm{O}$ recurso deveria promover a curiosidade e incentivar o diálogo em aula. Conclui a produção, em 2014, e registrei o uso do recurso, pela primeira vez, em uma oficina, no ano de 2015. Também publiquei em um Caderno de Formação do Ministério da Educação (PARENTE, 2015), relatando minhas experiencias com práticas investigativas no ensino de ciências. Mas, naquele momento, o processo de produção do recurso não foi o foco de pesquisa.

Perguntas como "quanto tempo levaste para construir esse recurso? como construíste esse recurso?" foram dirigidas a mim, após apresentá-lo a um grupo de professores, na disciplina Afetividade e construção de conhecimento científico, desenvolvida, pelo segundo autor do presente artigo, no Programa de Pós-graduação em Educação em Ciências e Matemática (PPGECM), do Instituto de Educação Matemática e Científica (IEMCI), no ano de 2017. Tais perguntas motivaram a realização do presente estudo. Na disciplina, compartilhávamos leituras e discussões sobre a aprendizagem, na perspectiva histórico-cultural, e refletíamos sobre o papel da imaginação e da criatividade na aprendizagem (MITJÁNS MARTÍNEZ, 2014a).

Assumi as perguntas como orientadoras da produção de um texto biográfico (NÓVOA, 2010). Esse texto foi discutido e aperfeiçoado, passando a incluir a descrição do processo de criação do experimento didático. Para a produção do texto, visando a construir o percurso da produção do recurso, utilizei memórias, fotos e notas de campo.

Sobre a abordagem biográfica, é importante compreender que ela se opõe ao modelo de formação pautado na racionalidade técnica ou modelo hegemônico de formação. Tal modelo dissocia o tempo de formação do tempo de ação do professor. Na abordagem biográfica, 
“interessa é que o indivíduo construa sua memória de vida e compreenda as vias que seu patrimônio vivencial lhe pode abrir: ao fazê-lo no presente, ele está formando-se (emancipandose) e projetando-se no futuro" (NÓVOA, 2010, p. 181). Também está autogerenciando a formação (LACERDA, 2002)

A pesquisa (auto)formativa biográfica levou em consideração que a narrativa não é a história literal dos fatos, mas uma construção mediada pelo presente (CONNELLY; CLANDININ, 2011). Desse modo, a "biografia elabora-se hoje, num tempo e num espaço concretos, sempre numa perspectiva retrospectiva e com uma preocupação teórica claramente definida" (NÓVOA, 2010, p. 181). Assim, a partir do texto de campo (texto biográfico) e com as considerações analítico-interpretativas (CONNELLY; CLANDININ, 2011), produzi o texto de pesquisa (biografia do percurso de produção do recurso didático). Na figura 1, a seguir, apresento uma síntese desse processo desenvolvida neste estudo:

Recurso didático:

Experimento investigativo para ensinar densidade e força de empuxo

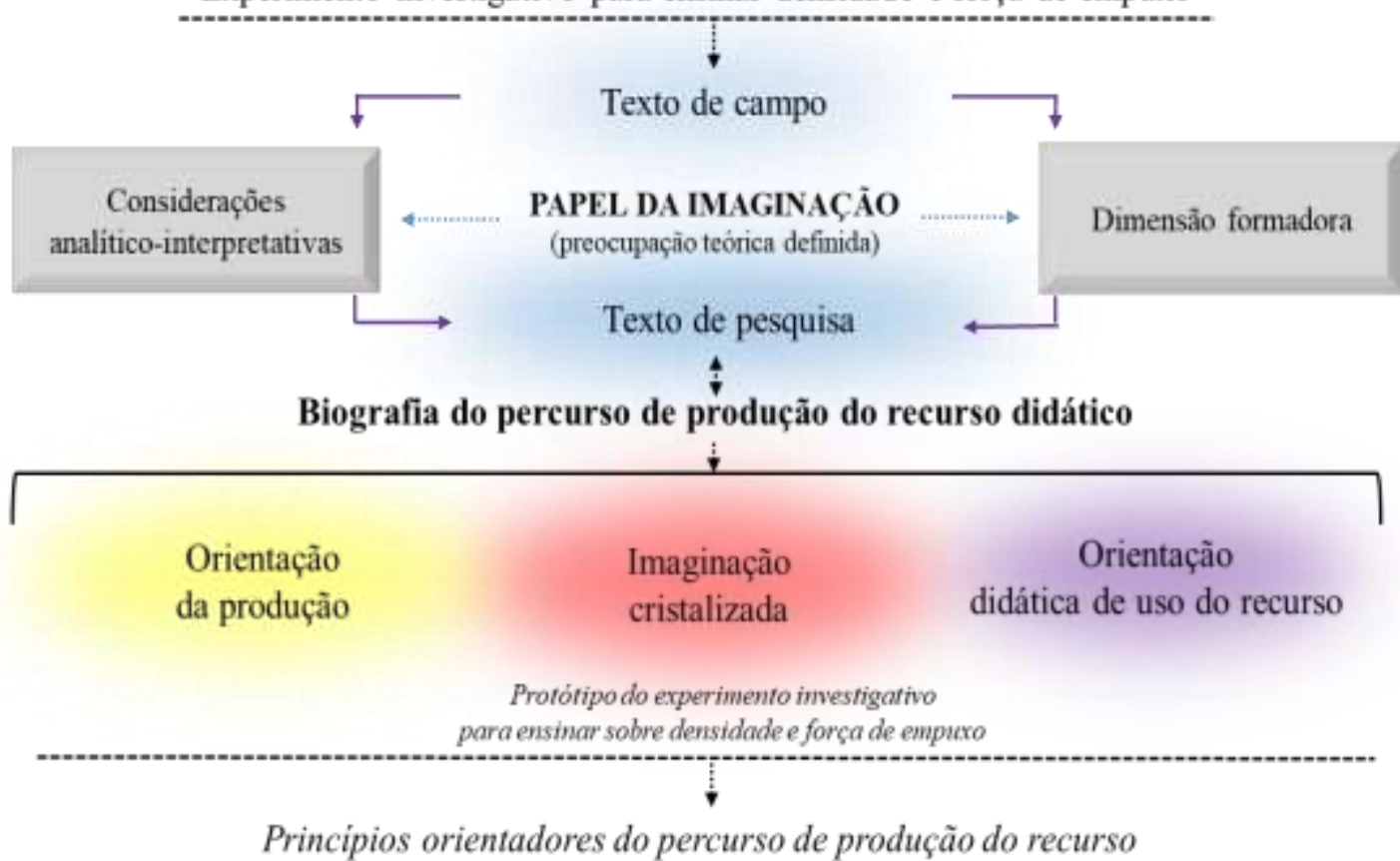

Figura 1 - Síntese esquemática da pesquisa (auto)formativa biográfica

Fonte: Parente (2020).

No texto de pesquisa, o percurso de produção do recurso didático está organizado do seguinte modo: apresento o processo analítico-interpretativo da biografia do percurso de produção do recurso, indicando a orientação da produção, a imaginação cristalizada e a orientação didática, incluindo os desafios enfrentados e as soluções propostas. 
Simultaneamente, realizo reflexões fundamentadas na perspectiva histórico-cultural de Vygotsky e González Rey, relacionadas com os dilemas do processo de criação. Finalizo o texto de pesquisa com uma síntese, para apresentar os princípios orientadores do percurso de produção do recurso.

Esclareço que este não é um estudo sobre a subjetividade do professor (MITJÁNS MARTÍNEZ, 2014b), portanto, não tratou de estudar os processos subjetivos envolvidos no percurso de criação do recurso. Entretanto, contextualiza o fenômeno biográfico narrativo no diálogo com os conceitos de imaginação e criatividade, tal como formulados na Teoria da Subjetividade.

\section{ANÁLISES E RESULTADOS}

Na LICML, compartilho de uma atmosfera favorável à investigação de minha prática pedagógica e busco coerência entre o ensino que realizo e a formação que desejo para os licenciandos. A meu ver, esta formação inclui a ação do professor comprometida com os conteúdos de ensino, com os conhecimentos pedagógicos e com a aprendizagem dos estudantes. Desse modo, a prática pedagógica transforma-se em espaço de pesquisa. Nela, surgem casos ou situações singulares, que tornam necessária a reflexão do professor (ANDRÉ, 2016). Tais situações, exigem invenção de recursos profissionais. Sobre isso, Contreras (2002, p.108) afirma que

[...] recursos profissionais não se explicam pelo domínio de um repertório técnico ou de determinadas regras para a tomada de decisões. Ao contrário, requer dos profissionais a capacidade de criar novas perspectivas, de entender os problemas de novas maneiras não previstas em seu conhecimento anterior.

Desse modo, entendo que o recurso não foi produzido por acaso. Minhas intenções que resultaram nessa produção, nem todas conscientes, naquele momento, expressam-se, quando interpreto os textos de campo e elaboro os princípios orientadores do percurso de produção do recurso didático. Além disso, a criação do recurso não foi alheia às situações adversas do processo, demonstrando que os dilemas a constituem, bem como a proposição de soluções "quando a imaginação se converter ou se cristalizar em imagens exteriores" (VYGOTSKY, 2014, p.30), conforme se refere o autor ao ciclo completo da atividade ou à concretização das ideias. 


\section{A intenção de ensinar sobre o conceito de densidade: equívocos, aprendizagens e possibilidades de produção do recurso didático}

No tema Estágio Temático em Educação em Ciências, Matemática e Linguagem IV, um grupo de licenciandos do curso de LICML apresentou uma atividade que tinha a intenção de introduzir o conceito de densidade no ensino de ciências para os anos iniciais. Eles consideraram que a observação e o diálogo sobre o fenômeno da flutuação de frutas e legumes eram meios apropriados para compartilharem experiências significativas sobre o conceito de densidade com os estudantes. Colocaram frutas, grãos e legumes na água e pretendiam ensinar às crianças que aqueles que afundassem eram mais densos que a água e os que se mantivessem na superfície do líquido eram menos densos. Desse modo, o grupo recorreu ao conceito de densidade para explicar o fato de alguns vegetais afundarem e outros não.

Dentre os vegetais, os licenciandos usaram grãos de feijão. Nesse caso, entretanto, alguns grãos flutuaram, enquanto outros afundaram. Considerando a intenção dos licenciandos de ensinar sobre a densidade dos materiais, questionei: "por que os grãos de feijão assumem comportamentos diferentes em água?”. Se a densidade é uma propriedade específica do material, seria esperado o mesmo comportamento para todos os grãos de feijão. Uma vez que isso não aconteceu, perguntei: "é pertinente estudar a densidade, recorrendo à flutuação de grãos de feijão?".

O conceito de densidade é definido como a relação " $\mathrm{m} / \mathrm{V}$ ”, isto é, "indica a quantidade de massa de uma substância contida em um certo volume da mesma. Para cada substância esta relação é uma constante [...]" (ROMANELLI; JUSTI, 1997, p. 32). A relação constante em " $\mathrm{m} / \mathrm{V}$ " significa que a densidade é uma propriedade intensiva da matéria e, deste modo, não depende do tamanho da amostra. Sobre isso, Atkins e Jones (2012, p. 8) explicam:

\footnotetext{
A densidade de uma substância independe do tamanho da amostra, porque quando o volume dobra, sua massa também dobra, mas a razão entre a massa e o volume permanece constante. A densidade é, portanto, uma propriedade intensiva.
}

O questionamento que fiz aos licenciandos assumiu como referência o propósito que eles tinham de planejar uma atividade para ensinar o conceito de densidade. Se os grãos de feijão são constituídos da mesma matéria deveriam assumir o mesmo comportamento, já que os grãos eram semelhantes. Contudo, o comportamento diferente dos grãos demandava uma explicação.

Marie Curie (CHAVANNES, 2007, p. 103, grifos meus) conversou com crianças sobre a flutuação de corpos/objetos de vidro (ou seja, constituídos do mesmo material), fazendo o uso 
da expressão "menos denso que". Ela explicou a diferença de comportamento observado entre um vidro (caco de vidro) e um objeto (cristalizador) feito de vidro.

Há corpos que flutuam e corpos que afundam. Para que um corpo flutue, é preciso que ele seja menos denso que a água. O que acontece se colocarmos vidro na água? Ele afunda. Entretanto, se colocarmos esse cristalizador, ele não afunda. É por causa de sua forma. É preciso, para que um corpo afunde, que ele seja maciço, que não seja oco.

Na narrativa, Marie Curie explica a flutuação dos corpos, referindo-se ao conceito de densidade. Explica que isso só é possível em se tratando de corpos maciços. Essa é uma condição que deve ser assegurada. Caso contrário, torna-se necessário considerar outros fatores. O cristalizador, feito de vidro, não afundou por causa de sua forma e não de sua densidade.

No caso dos grãos de feijão, usados pelos licenciandos, não havia algo perceptível a que pudessem atribuir o comportamento observado. Mas compreendi que havia alteração nos grãos que flutuaram, questionei o grupo, e incentivei que refletisse sobre o comportamento observado.

Um material sólido (corpo/objeto) em contato com um líquido (desde que não reajam entre si) sofre ação da pressão do líquido em que foi colocado. A pressão do líquido sobre a superfície do material assume direções diversas, sendo que as componentes de força não perpendiculares à superfície do corpo cancelam-se mutuamente. Assim, "quando um líquido pressiona uma superfície, há uma força resultante dirigida perpendicularmente à superfície" (HEWITT, 2002, p. 233). A força exercida sobre a superfície inferior (mais funda) do corpo, que assume a direção de baixo para cima, perpendicular à superfície do líquido, é definida como força de empuxo. Já a força que assume a direção de cima para baixo, é a força peso. Essa é também perpendicular à superfície do líquido.

A força de empuxo está associada com "uma aparente perda de peso sofrida pelos objetos quanto estão submersos em um líquido" (HEWITT, 2002, p. 234). Quando um corpo/objeto é colocado em um líquido, além de se tornar, aparentemente, mais leve, eleva o nível do líquido. A elevação do nível refere-se ao volume de líquido deslocado por ele. Quando o objeto fica completamente submerso (ou seja, abaixo da superfície do líquido), o volume de líquido que ele desloca é igual ao seu volume. O volume de líquido deslocado por um objeto é importante para a compreensão da força de empuxo. Segundo Hewitt (2002, p. 235):

Essa relação entre o empuxo e o líquido deslocado foi descoberta no século terceiro a.C. pelo cientista grego Arquimedes. Ele anunciou assim: Um corpo imerso sofre ação de uma força de empuxo dirigida para cima e igual ao peso do fluido que ele descola. [...] Se um corpo imerso desloca 1 quilograma de fluido, a força de empuxo que atua sobre ele é igual ao peso de um 1 quilograma. 
Portanto, a força de empuxo é definida pelo peso do volume do líquido que o corpo deslocou. A interação resultante das forças opostas que atuam na superfície do corpo, ou seja, da força peso do corpo colocado no líquido e da força de empuxo, definida pelo peso do volume de líquido deslocado pelo corpo imerso (e contrária a força peso), é que permite compreender a flutuação de um sólido em um líquido. Assim, "se um objeto irá afundar ou flutuar em um líquido dependerá de como a força de empuxo se compara com o peso do objeto" (HEWITT, 2002, p.236).

Em relação ao uso dos conceitos de densidade e força de empuxo, para o fenômeno da flutuação de objetos em água, concordo com Farias (2004, p. 44): “o professor deverá lembrar que, rigorosamente falando, o que decide se um corpo flutua ou afunda não é a densidade, mas a relação entre o seu peso e o empuxo oferecido pelo fluido no qual está imerso".

O conceito de densidade pressupõe uma relação entre a quantidade de massa do corpo/objeto contida em um determinado volume. Em um nível micro, posso afirmar que é “massa dos átomos e os espalhamentos entre eles" (HEWITT, 2002, p. 217). Portanto, não é um conceito que para a sua compreensão supõe a relação comparativa entre corpos/objetos.

Assim, considerei recomendado estudar o comportamento das frutas e vegetais, inclusive o comportamento dos grãos de feijão, pela interação entre as forças peso e empuxo. Nesse caso, o conceito de densidade, que para a análise em questão, necessitaria de corpos maciços e homogêneos, só poderia ser utilizado como complementar ao conceito de força de empuxo. Esse último deveria ganhar centralidade na explicação do evento observado, uma vez que cada um dos grãos de feijão apresentava estruturas ligeiramente diferentes, que se mostravam relevantes para o seu comportamento, ao serem postos na água.

Portanto, é incoerente recorrer à observação da flutuação de dois corpos/objetos, constituídos do mesmo material, sem assegurar-se que eles são maciços, inclusive quando são aparentemente semelhantes, para afirmar, a partir da comparação entre eles e o líquido em que estão imersos, que um é mais denso que o outro. Dois ou mais corpos/objetos constituídos do mesmo material terão a mesma densidade, mas isso não garante que assumirão o mesmo comportamento em um líquido. O comportamento dependerá de sua forma, como explicou Marie Curie, na narrativa de suas aulas, particularmente da força resultante entre o peso do corpo e a força de empuxo que atuará nele.

Entretanto, é muito comum observar erros em atividades presentes em livros didáticos, pois tratam da flutuação de objetos a partir do conceito de densidade, desconsiderando que esse se fundamenta nas "massas dos átomos e os espalhamentos entre eles" (HEWITT, 2002, p. 
217). Na ausência da compreensão conceitual aqui mencionada, é inevitável o erro. Considero importante que os professores dos anos iniciais sejam alertados a esse respeito, pois os estudantes podem aprender concepções equivocadas, que dificultam aprendizagens posteriores de outros conceitos científicos. Criar condições favorecedoras para a reflexão de professores em formação (inicial ou continuada) sobre as diferenças entre os conceitos de densidade e força de empuxo foi a motivação inicial para criar o recurso didático.

As perguntas que fiz aos licenciandos tornaram-se um desafio para eles. Eles não suspeitaram de alteração na constituição dos grãos e expressamente entendiam o conceito de densidade como resultante da observação empírica do comportamento dos corpos/objetos colocados em líquido. Explorei a situação e dialoguei sobre os conceitos de densidade e força de empuxo com a turma. Os licenciandos, por sua vez, optaram por estudar mais sobre o conceito de densidade e projetaram outras atividades de ensino.

As dúvidas, comentários e dificuldades manifestadas pelos licenciandos inspiraram-me a propor um recurso didático que permitisse a investigação dos conceitos de densidade e força de empuxo, visando a estabelecer relações e diferenças. Contudo, meu propósito demandou tempo, persistência e não foi produzido no período em que aquela interação com os licenciandos se desenvolveu.

De início, a elaboração da interpretação para o comportamento dos grãos de feijão orientou meu processo de reflexão e de proposição do recurso. Era possível explicar o comportamento dos grãos de feijão que afundaram, fazendo uso de dois conceitos, já que grãos de feijão maciços possuem valores de densidade maior do que o da água, embora a relação de comportamento entre a força peso e a força de empuxo fosse mais recomendada, pelas razões que expus, anteriormente.

Era possível explicar o comportamento dos grãos de feijão que flutuaram usando o conceito de força de empuxo e força peso. Eles possuíam a mesma forma dos grãos que afundaram, entretanto, flutuaram. Considerando a compreensão de força de empuxo, é possível pressupor que os grãos que flutuaram deslocaram um volume de água cujo valor de massa era igual a massa do seu próprio corpo (grão), resultando, portanto, na força de empuxo maior que a força peso. Provavelmente, a massa do corpo do feijão que flutuou era menor que a massa do feijão que afundou, sendo que ambos possuíam a mesma forma. $\mathrm{Na}$ figura 2 , a seguir, um esquema explicativo: 


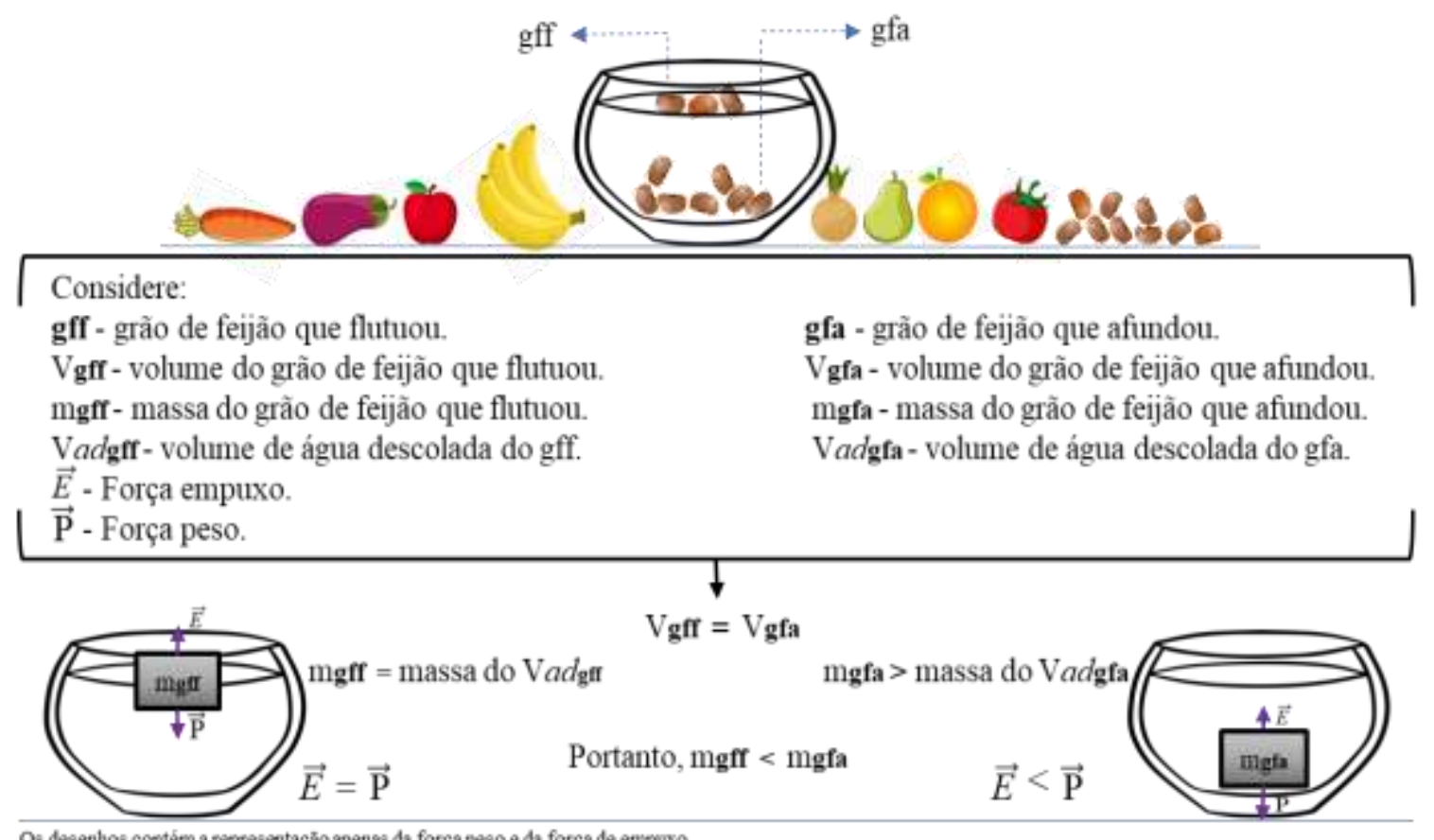

Os desenhos coutém a representação apenas da força peso e da força de empaxo.

Figura 2 - Esquema explicativo para a flutuação de grãos de feijão na água Fonte: Parente (2020).

Compreendo que a explicação do comportamento dos grãos observado gerou uma orientação teórica da produção do recurso didático, pois o comportamento diferente de um mesmo material com pequenas mudanças estruturais permitiu diferenciar os conceitos de densidade e força de empuxo.

A explicação do fenômeno implicou conhecimentos teóricos, os quais constituíram meu pensamento, produzindo novos sentidos que orientaram meu projeto de criação.

\footnotetext{
Toda forma de conhecimento é uma produção subjetiva e pode ser considerada como libertadora, sadia e facilitadora do desenvolvimento, sempre que represente um novo caminho de produção subjetiva, assumido de forma ativa pela pessoa como sujeito da ação. A ação e a produção intelectual representarão processos imaginativos de profunda implicação emocional, que serão parte da configuração subjetiva da ação na qual o conhecimento é gerado (GONZÁLEZ REY, 2014, p. 46).
}

Deste modo, a partir das considerações analítico-interpretativas, formulo o seguinte orientador da produção:

Criar condições facilitadoras para a compreensão dos conceitos de densidade e força de empuxo pelos estudantes, incentivando sua curiosidade e imaginação, por meio da solução (individual elou coletiva) de problemas, formulação e teste de hipóteses. A primeira maneira que imaginei para viabilizar isso, concretamente, foi simular o fenômeno observado com os feijões, usando outros materiais. 
Minha intenção de contribuir com a aprendizagem dos licenciandos, seguida pela produção de uma representação do fenômeno, inspirada em sua explicação teórica, foram aspectos fundamentais para que eu pudesse vislumbrar a possibilidade de produção do recurso.

O ensino não é uma atividade técnica, mas pressupõe, entre outras condições, um conhecimento profissional que inclui o "saber transformar o conhecimento do conteúdo em ensino" (GATTI, et al., 2019, p. 191). Não depende somente do conhecimento do conteúdo conceitual, pois a atividade de criação do professor implica a dimensão complexa de sua constituição formativa. Nesse sentido, “a imaginação se encontra como que no ponto crucial onde a percepção, a memória, a geração de ideias, a emoção, a metáfora e, sem dúvida, outros aspectos de nossa vida se cruzam e interagem" (EGAN, 2007, p.13).

\section{Explorando possibilidades: em busca de um artifício}

O uso do feijão poderia ser fonte de incompreensões dadas as condições alteradas dos grãos. Os grãos que flutuaram estavam brocados (apresentavam pequenos orifícios internos), o que justifica o comportamento observado. Continuando o desenvolvimento do recurso didático, não foi problema obter materiais maciços que afundassem em água como: esferas de vidro (bolas de gude ou petecas, como são conhecidas no estado do Pará), esferas de plástico (bolas de borracha e de silicone), esferas de madeira e aço. Mas, era necessário encontrar uma maneira de fazer que esses mesmos materiais flutuassem.

A leitura do texto de Abib (2013) me inspirou. Tal a autora relatou uma situação na qual solicitava aos estudantes que introduzissem esferas de vidro em um recipiente plástico, que funcionava como uma espécie de barco, de modo que as esferas pudessem ser transportadas por esse recipiente, de um lado para o outro, dentro de uma bacia plástica com água.

A partir da reflexão sobre o texto, imaginei usar uma garrafa plástica para fazer com que esferas de vidro flutuassem. Uma garrafa plástica, de capacidade de $300 \mathrm{ml}$, pode conter no máximo 48 esferas de vidro de volume, aproximadamente, igual a $3 \mathrm{ml}$, considerando entre elas espaços com ar. Contudo, a experiência demonstrou que a garrafa cheia de esferas ia ao fundo.

Também imaginei substituir as esferas de vidro por esferas de um outro material, só que algumas impossibilidades surgiram. As esferas de plástico (silicone e borracha) não poderiam ser introduzidas na garrafa devido às suas dimensões. As esferas de aço, por sua vez, eram menores que as esferas de vidro, entravam com facilidade pelo orifício da garrafa plástica, mas sua massa era bem maior em relação ao mesmo volume da esfera de vidro. 
A garrafa plástica era um artifício que poderia fazer um conjunto de objetos sólidos, maciços e mais densos que a água, flutuarem. Mas que objeto introduzir na garrafa? O desafio agora consistia em obter objetos que, introduzidos na garrafa, a preenchessem e, ainda assim, a garrafa com os objetos flutuassem.

Pensar na garrafa como artifício para fazer flutuar objetos mais densos que a água, sem alterá-los, permitiu-me a produção de novas ideias para a produção do recurso. Essas ideias alteravam a primeira maneira que imaginei para viabilizar, concretamente, o recurso didático. Assim, enuncio uma segunda orientação da produção:

Pretendi usar um artifício (garrafa plástica) para assegurar comportamentos diferentes para um mesmo objeto (não mais procurando simular o comportamento dos grãos de feijão) $e$ dispor de uma esfera mais densa que a água. Nessa projeção, era possível antecipar a potencialidade do recurso em incentivar a curiosidade, explorar ideias e promover o debate produtivo sobre os conceitos de força peso e força de empuxo.

Importa compreender que as orientações da produção são a expressão de ideias novas. Para González Rey (2014, p. 47), é a manifestação da imaginação intelectual. Sobre isso, ele escreveu: "a imaginação intelectual tem como ponto forte a produção de ideias novas diante de fatos, leituras ou outras ideias, sem que possa ser estabelecido uma relação direta entre as novas ideais e essas fontes".

\section{Investigando a massa e o volume de esferas constituídas de materiais diferentes: prevendo o uso de outros materiais}

Que objeto eu poderia introduzir na garrafa plástica, com densidade maior que a da água, que a preenchesse sem que ela afundasse? A alternativa que assumi foi pensar a partir do uso da esfera de plástico.

$\mathrm{O}$ volume das esferas de plástico disponíveis $(\mathrm{V} \approx 15 \mathrm{ml})$ era maior em relação ao volume das esferas de vidro $(\mathrm{V} \approx 3 \mathrm{ml})$. No referido volume da esfera de plástico, a massa era maior que a da esfera de vidro. Contudo, para o volume de $3 \mathrm{ml}$, igual ao das esferas de vidro, a massa da esfera de plástico era menor $(\mathrm{m} \approx 3,13 \mathrm{~g})$, se comparada à massa da esfera de vidro $(\mathrm{m} \approx 7,32 \mathrm{~g})$. Essa diferença, obtida ao comparar as duas esferas, permitiu imaginar que a esfera de plástico seria o objeto apropriado para o meu propósito. Porém, questionei-me sobre como colocar isso em prática, já que não era possível fazer o teste experimental. A seguir, na figura 3, informo sobre a massa e o volume das esferas disponíveis (vidro e plástico) e suas diferenças. 


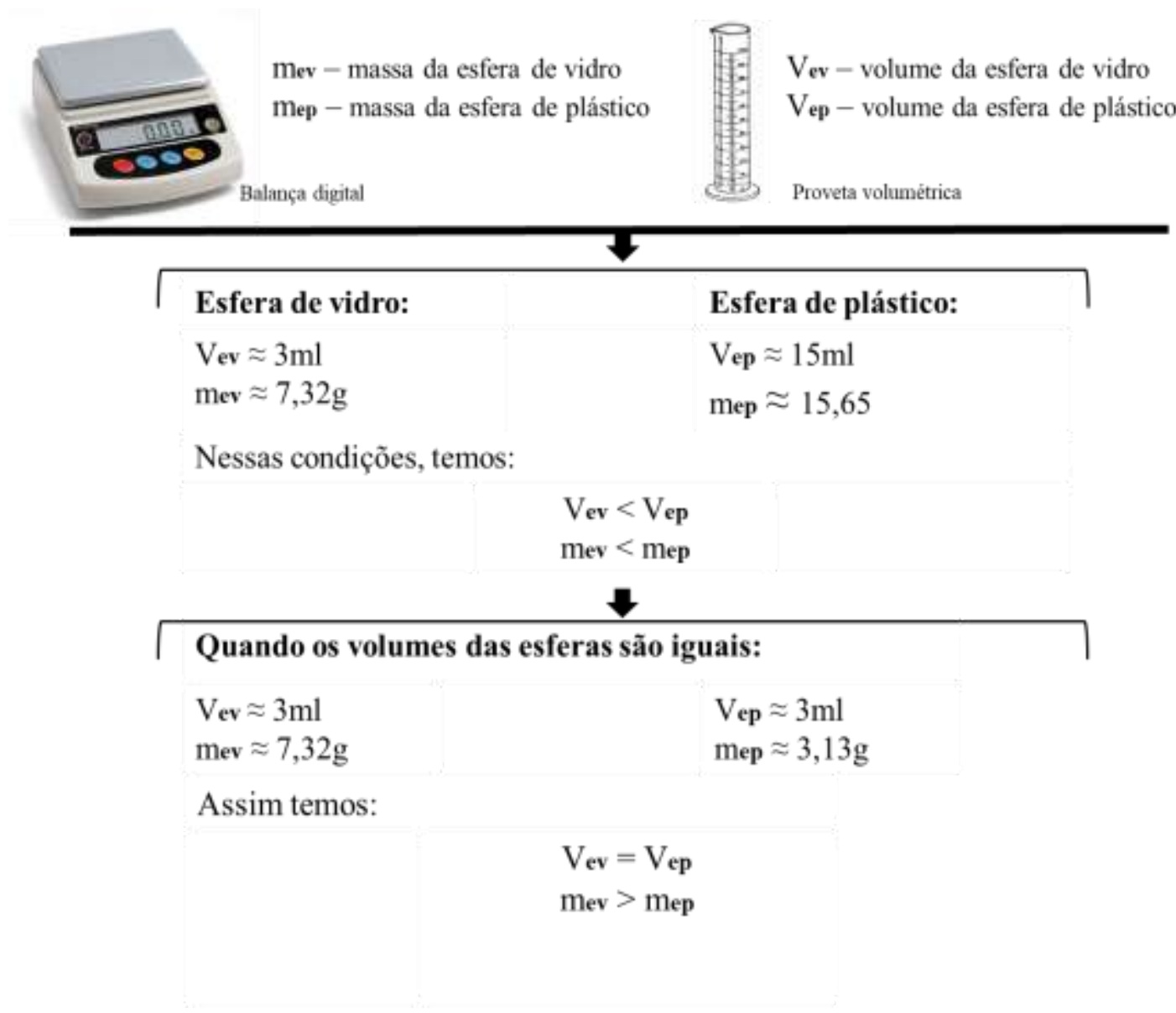

Figura 3 - Informações sobre massa e volume das esferas de vidro e de plástico. Fonte: Parente (2020).

Com base nas informações disponíveis, na figura 2, duas questões me pareceram fundamentais.

1. Qual é o número de esferas de vidro que a garrafa suporta, sem ir ao fundo? Com a informação sobre o número de esferas de vidro que a garrafa podia conter, sem afundar, seria possível ter ideia da massa total de esferas de outro material para preenchê-la. Introduzi o número máximo de esferas na garrafa, o que totalizou 48 unidades. Para saber o número de esferas que a garrafa suportava, sem que fosse ao fundo, retirei as petecas, uma a uma, observando o comportamento da garrafa na água. Com 39 petecas, a garrafa não afundava mais.

2. Qual é a massa da quantidade de esferas que a garrafa contém, sem ir ao fundo? Sabendo o número máximo de esferas que a garrafa podia conter, foi possível calcular a massa correspondente a esse número, a partir do valor de massa de uma unidade da esfera de vidro. Uma esfera tinha a massa de 7,32 g, logo a massa de 39 esferas de vidro era de 285,48 g.

No quadro 1, observa-se que, para o volume aproximado de $3 \mathrm{ml}$, a massa da esfera de plástico é de aproximadamente 3,13 g. Assim, 48 esferas de plástico, quantidade suficiente para 
preencher a garrafa, possuem um valor de 150, $24 \mathrm{~g}$. A massa de 150, $24 \mathrm{~g}$ é inferior a 285, 48 g. Portanto, seria possível a garrafa flutuar com o uso de 48 esferas de plástico. Dessa forma, tornava-se possível produzir um fenômeno cuja explicação demandasse conteúdos de ensino e a problematização dos conceitos de força peso, força de empuxo e densidade.

Além de tornar viável o projeto de construção do recurso com o uso das esferas de plástico, a partir do percurso de produção de ideias apresentadas, também imaginei uma condição que satisfizesse a busca de outros objetos constituídos de quaisquer outros materiais, compreendendo que, se a garrafa de plástico fosse preenchida com 48 esferas de outro material, de volume aproximado a $3 \mathrm{ml}$ e massa igual ou menor a 5,94 g, ela não afundaria, pois a soma da massa dessas esferas, igual a 285,12 g seria menor que 285,48 g, que é referente à massa que a garrafa poderia conter, sem ir ao fundo.

A resposta aos dois questionamentos permitiu-me imaginar a viabilidade de utilizar esferas de plástico para o propósito estabelecido e também prever o uso de esferas de outro material, desde que o valor de massa fosse igual ou menor que 5,94 g, em um volume de $3 \mathrm{ml}$. A partir de tais investigações e reflexões, propus uma terceira maneira de viabilizar, concretamente o recurso didático:

Imaginar uma circunstância em que mesmo cheia de esferas feitas de outro material a garrafa não afundasse. Cada esfera do outro material haveria de ter uma massa menor que a da esfera de vidro. Se a massa da esfera de vidro era de 7,32 g, a massa da esfera de outro material poderia ser igual ou menor a 5,94 g. Cada esfera de outro material teria que conter 1,38 g a menos que a massa de cada esfera de vidro. Na imaginação, havia criado o recurso, mas era preciso concretizá-lo.

A biografia do percurso de produção do recurso permite refletir sobre a orientação de produção que assumi. Foi em função das ideias, inclusive com leituras e com reflexões sobre o assunto, investigando os objetos disponíveis (esferas de materiais diferentes) e comparando suas massas, que viabilizei uma solução para o problema enfrentado. $\mathrm{O}$ cálculo da massa que as esferas precisariam ter para, ao mesmo tempo, preencher a garrafa plástica e garantir a sua flutuação, passou a orientar minha busca do objeto, tendo em vista sua concretização (imaginação cristalizada).

As relações estabelecidas entre as esferas de plástico e vidro disponíveis geraram informações que permitiam pensar na viabilidade de construção de um protótipo do recurso didático. Todavia, a esfera de plástico deveria ser de mesmo volume que a esfera de vidro. Cabe lembrar que as esferas de plástico disponíveis eram bem maiores que as de vidro, praticamente o quíntuplo de seu volume, e não entravam pela "boca" da garrafa de plástico. 
Novas explorações foram realizadas, sendo relevante destacar que "a insistência quase sempre está relacionada com a capacidade imaginativa de ver as soluções para os problemas" (EGAN, 2007, p.13). Dito de um outro modo, se a imaginação é um processo motivado, ela também é capaz de motivar a ação. A persistência é um indicador da motivação. Até então dispunha de duas possibilidades: esferas de plástico e esferas de madeira. Para as esferas de plástico, o desafio era encontrá-las com um volume igual ao das esferas de vidro. Para as de madeira, ainda que não fosse impossível produzi-las na dimensão ideal, haveria dificuldade e, nas circunstâncias do experimento, dependeria do trabalho artesanal de um profissional marceneiro, que, ao ser contatado, afirmou não possuir os instrumentos adequados.

Fui ao comércio, entrei e sai de lojas, procurando esferas de plástico do mesmo volume das esferas de vidro. Entretanto, não tive êxito. Comprei esferas de vidro maiores, na esperança de encontrar as de plástico de tamanho correspondente, e até pensei utilizar outro recipiente de plástico, diferente da garrafa de $300 \mathrm{ml}$. Diante da impossibilidade de obter o material nas condições previstas no planejamento, não era possível construir o protótipo.

\title{
Imaginação cristalizada: um protótipo do experimento investigativo para ensinar densidade e força de empuxo.
}

Retirei do texto de campo o trecho a seguir, referente à ocasião em que me foi possível voltar a pensar na concretização das ideias sobre o recurso.

\begin{abstract}
No ano de 2014, concorri ao edital do projeto de monitoria para ter auxílio nas atividades do Laboratório de Ciências. Duas discentes, que cursaram o Estágio temático, tornaram-se bolsistas. Juntas revolvemos retomar as atividades do grupo que cada discente havia participado, inserindo modificações decorrentes de nossas avaliações. Agrupamos os materiais produzidos por um dos grupos no Estágio Temático de um modo diferente do que antes havia sido feito, agora visando à abordagem das noções de densidade com as crianças. Ao visualizar o agrupamento, identifiquei, na primeira linha do grupo materiais que afundavam, a esfera de biscuit, praticamente com o mesmo volume da esfera de vidro. Recordei da esfera de plástico que busquei para a produção do material visando a abordar as noções de densidade e empuxo. Peguei a esfera de biscuit da segunda linha do mesmo grupo e levei à balança. Sua massa foi de 4,04 g, menor 3,28 $\mathrm{g}$ em relação à de vidro. A massa de biscuit é moldável e endurece na presença de ar. Então, confeccionamos esferas de biscuit, de modo que, mesmo com as 48 esferas de biscuit, a garrafa flutuava.
\end{abstract}

A organização a que me referi está representada, na Figura 4, a seguir: 


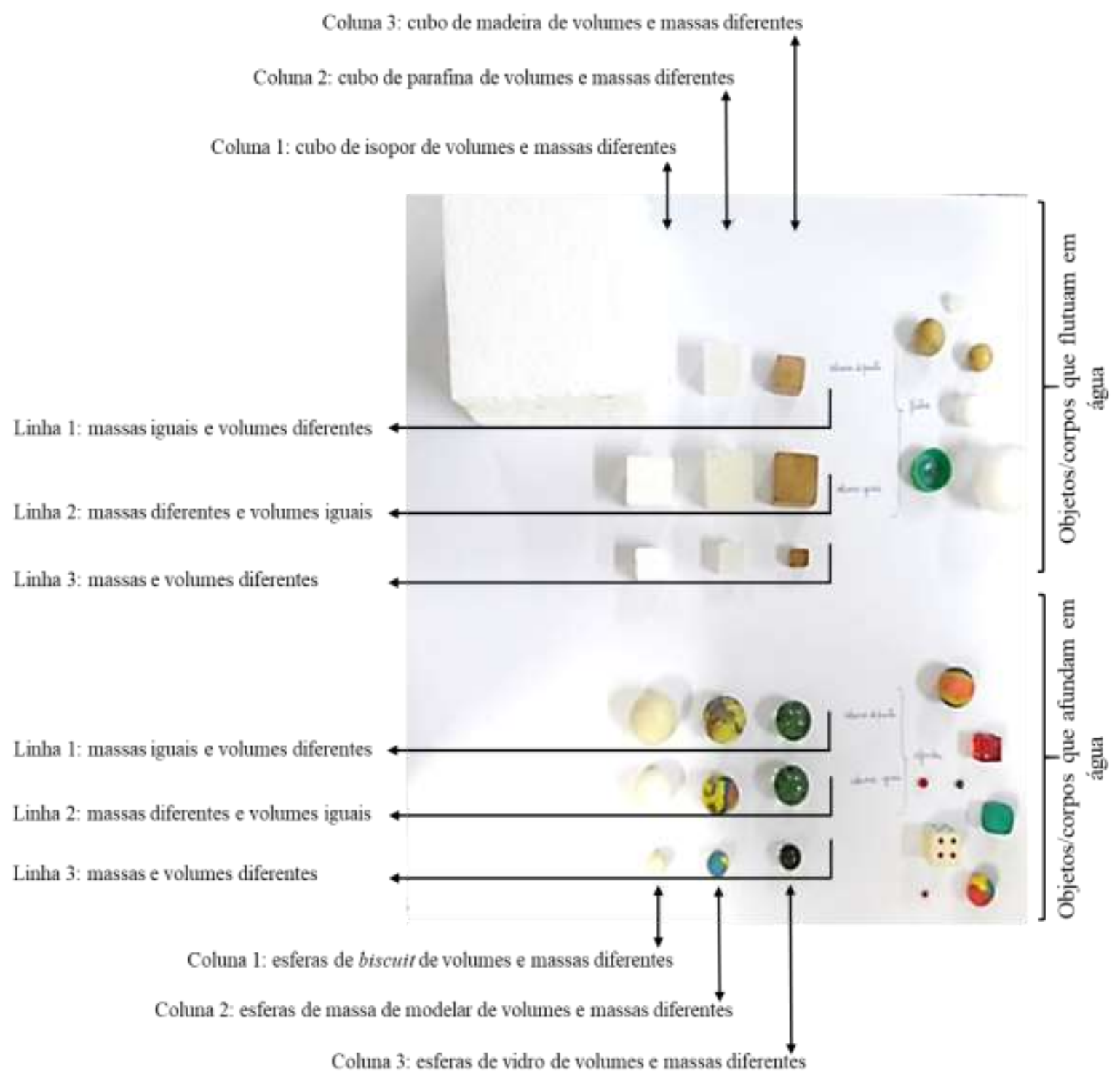

Figura 4 - Imagem de objetos constituídos de materiais diferentes, agrupados conforme seu comportamento na água.

Fonte: Parente (2014).

No agrupamento de objetos que afundam em água, constam, na coluna 1, as esferas de biscuit $^{4}$ de tamanhos diferentes. Note que, na linha 2, desse mesmo grupo, é possível identificar três esferas constituídas de materiais diferentes (biscuit, massa de modelar e vidro). Com o uso das esferas de biscuit, produzi um recurso didático (Figura 5) que possibilitava ensinar os conceitos de força de empuxo e densidade dos materiais.

\footnotetext{
${ }^{4}$ Biscuit é uma massa moldável constituída de amido. É vendida em armarinhos ou lojas de artesanatos.
} 

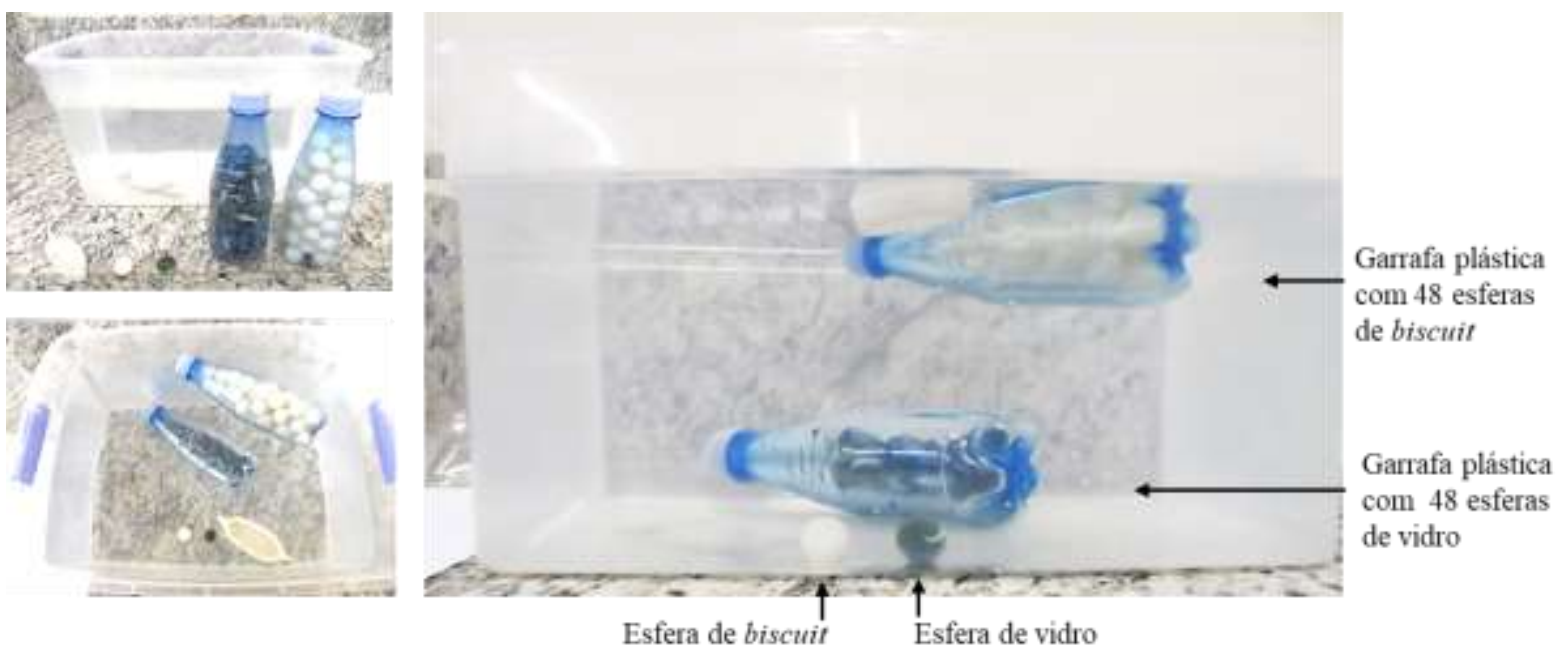

Figura 5 - Recurso didático.

Fonte: Parente (2015).

O recurso didático (Figura 5) já foi utilizado com estudantes de graduação e compartilhado com professores da educação básica. Em geral, foi apresentado aos estudantes fazendo-os observar o fenômeno da flutuação. No primeiro momento, introduzindo a peteca de vidro em um recipiente de plástico contendo água. Em sua maioria, os estudantes conhecem o comportamento da esfera de vidro na água. No segundo momento, introduzindo a garrafa plástica contendo esferas de vidro. Eles não demonstram dúvida sobre o comportamento esperado e afirmam que a garrafa contendo as petecas irá afundar. No terceiro momento, apresentando a esfera de biscuit. A maioria desconhece o material e pergunta de que é feito. Em geral, preferem não opinar sobre o comportamento da esfera, que observam, em seguida, afundar na água; e, por último, apresentando a garrafa contendo as esferas de biscuit, que ao ser introduzida na água, se comporta de maneira diferente da garrafa com esferas de vidro, contrariando as expectativas dos estudantes. Essa observação provoca questionamentos como: considerando que uma esfera de vidro afunda e um garrafa com 48 esferas de vidro também afunda, se uma esfera de biscuit afunda na água, por que uma garrafa com 48 esferas de biscuit não afunda?

O experimento investigativo se fundamenta na seguinte orientação didática de uso do recurso.

Propor a situação didática para provocar a curiosidade e a indagação dos estudantes, ao se defrontarem com um problema, e incentivar a investigação do fenômeno, mediando o interesse de exploração suscitado nos participantes. Curiosos, os estudantes poderão usar sua imaginação para explorar o fenômeno, refletir sobre como tirar as esferas da garrafa, medir o volume delas, usar balanças etc. e, com isso, formular e testar várias hipóteses. Isso seria 
diferente de apresentar, para começar, a definição dos conceitos e o fenômeno da flutuação como sua ilustração. Além disso, a situação deveria possibilitar introduzir, intencionalmente, discussões qualitativas, visando ao desenvolvimento da aprendizagem dos conceitos de densidade e força de empuxo. O recurso permite ainda imaginar novas situações didáticas, modelando a investigação de outros problemas, como o naufrágio de uma embarcação, por excesso de carga ou passageiro.

A orientação da produção, a imaginação cristalizada e a orientação didática de uso do recurso constituem a biografia do percurso de produção e estão relacionadas à explicação teórica do fenômeno, às preferências didáticas e à imaginação do professor, constituindo os princípios orientadores do percurso de produção. Ao constituir-se pesquisador de sua prática, ao imaginar e ao viabilizar um modo de tornar ensinável conteúdos relacionados às necessidades dos estudantes, o professor produz conhecimentos e recursos didáticos.

\section{CONSIDERAÇÕES}

Compreendemos que o ensino não é uma atividade técnica, resultante da aplicação de uma determinada metodologia: requer tempo, investimento e condições para a elaboração de um modo de ensinar. A interação com os estudantes, seus equívocos, suas dúvidas e seus questionamentos pode mobilizar as emoções do professor, e, tornar-se para ele motivo de reflexão e de inspiração para imaginar e criar recursos de ensino. Essa reflexão também é motivada e fundamentada por toda a história de formação do professor: conhecimentos, princípios e valores pedagógicos que escolheu para pautar sua prática pedagógica.

A produção do recurso e, especialmente, a reflexão sobre o processo de sua produção, são momentos de aprendizagem e formação para o professor, pelas possibilidades de teorizar sobre os problemas, equacioná-los e propor-lhes soluções práticas. Esta criação acontece em vários momentos, começando pela emergência da ideia, como um desafio para a imaginação do professor, o que motiva sua atividade investigativa e criadora. A atividade exploratória, ao trazer soluções parciais, alimenta a imaginação do professor, ajudando-o a persistir até a concretização de seu projeto.

Finalizamos este artigo, indicando algumas de suas possíveis contribuições para a área de Educação em Ciências. Em primeiro lugar, a biografia do percurso de criação, incluindo os princípios que orientaram a produção do material didático, o recurso propriamente dito (imaginação cristalizada) e a orientação didática para seu uso podem inspirar professores a produzirem novos recursos didáticos para o ensino de ciências. 
Em segundo lugar, a pesquisa (auto)formativa biográfica mostrou-se uma possibilidade relevante de refletir e de discutir sobre a imaginação intelectual da professora, com potencial para inspirar professores a investigarem sobre outros processos de criação de materiais didáticos.

Por último, a elaboração de textos de pesquisa, com o objetivo de compartilhar biografias do percurso de produção de recursos didáticos, pode se constituir num espaço formativo para outros professores, valorizando a personalização do ensino e de seus materiais auxiliares.

\section{REFERENCIAS}

ABIB, M. L. V. S. Por que os objetos flutuam? Três versões de diálogos entre as explicações das crianças e as explicações científicas. In: CARVALHO, A M. P. (Org.) Ensino de ciências por investigação: condições para implementação em sala de aula. São Paulo: Cengage Learning, 2013. p 93-110.

ALVES, José Moysés; PARENTE, Andrela Garibaldi Loureiro. Linguagem e conhecimento, tema da formação inicial na Licenciatura Integrada em Ciências, Matemática e Linguagem. REAMEC - Rede Amazônica de Educação em Ciências e Matemática. v. 8, n. 1, p. 249267. jan/abr, 2020. ISSN: 2318-6674 .Disponível em: http://periodicoscientificos.ufmt.br/ojs/index.php/reamec/article/view/9861/pdf. Acesso em: 23 jul. 2020. Doi: http://dx.doi.org/10.26571/reamec.v8i1.9861.

ANDRÉ, A. Formar o professor pesquisador para um novo desenvolvimento profissional. In: ANDRÉ, M. (Org.). Práticas inovadoras na formação de professores. Campinas, SP: Papirus, 2016. p. 17-34.

ATKINS, Peter; JONES, Loretta. Princípios de química: questionando a vida moderna e o meio ambiente. Tradução Ricardo Bicca de Alencastro. 5. Ed. Porto Alegre: Bookman, 2012.

CHAVAnNES, Isabelle. Aulas de Marie Curie. Tradução Waldyr Muniz Oliva. São Paulo: Editora da Universidade de São Paulo, 2007.

CONNELLY, F. Michael; CLANDININ, D. Jean. Pesquisa narrativa: Experiência e História em Pesquisa Qualitativa. Tradução Grupo de Pesquisa narrativa e Educação de Professores ILEEL/UFU, Uberlândia: EDUFU, 2011.

CONTRERAS, José. A autonomia de professores. São Paulo: Cortez, 2002.

CUNHA, M. I. Ensino com pesquisa: a prática do professor universitário. Cadernos de Pesquisa, n.97, p.31-46, maio, 1996. ISSN 0100-1574. Disponível em: http://publicacoes.fcc.org.br/ojs/index.php/cp/article/view/802/813. Acesso em: 08 ago. 2020.

EGAN, K. Por que a imaginação é importante na educação. In: FRITZEN, C.; GLADIR, da S. C. (Orgs.). Infância e educação em debate. Campinas, SP: Papirus, 2007. p. 11-37. 
FAGUNDES, T. B. Os conceitos de professor pesquisador e professor reflexivo: perspectivas do trabalho docente. Revista Brasileira de Educação. v. 21, n. 65, p. 281-298, abr/jun 2016. ISSN 1809-449X. Disponível em: http://www.scielo.br/pdf/rbedu/v21n65/1413-2478-rbedu21-65-0281.pdf. Acesso em: 9 fev. 2019.

FARIAS, R. F. Utilizando uma luminária do tipo lava-luz para o ensino de densidade, dilatação térmica e transformações de energia. Química nova na escola, n.19, p. 43-45, maio 2004. ISSN 0104-8899. Disponível em: http://qnesc.sbq.org.br/online/qnesc19/a13.pdf. Acesso em: 12 de nov. 2017.

GATTI, Bernardete Angelina; BARRETTO, Elba Siqueira de Sá; ANDRÉ, Marli Eliza Dalmazo Afonso de; ALMEIDA, André Patrícia Cristina Albieri de. Professores do Brasil: novos cenários de formação. Brasília: UNESCO, 2019.

GONZÁLEZ REY, F. A imaginação como produção subjetiva: as ideias e os modelos da produção intelectual. In: MITJÁNS MARTINEZ, A.; ÁLVAREZ, P. (Orgs.) O sujeito que aprende: diálogo entre a psicanálise e o enfoque histórico-cultural. Brasília: Liber Livro, 2014. p. 35-61

GURGEL, I.; PIETROCOLA, M. Uma discussão epistemológica sobre a imaginação científica: a construção do conhecimento através da visão de Albert Einstein. Revista Brasileira de Ensino de Física, v..33, n. 1, p. 1602-1-1602-12, jan/mar 2011. ISSN 18069126. Disponível em: https://www.scielo.br/pdf/rbef/v33n1/24.pdf. Acesso em: 23 de ago. 2020. Doi: http://dx.doi.org/10.1590/S1806-11172011000100024

HEWITT, Paul G. Física conceitual. 9. ed. Porto Alegre: Bookman, 2012.

LACERDA, M. P. Por uma formação repleta de sentido. In: ESTEBAN, M. T.; ZACCUR, E. Professora-pesquisadora: uma práxis em construção. Rio de Janeiro: DP\&A, 2002, p. 7185.

LÜDKE, Menga; PUGGIAN, Cleonice; CEPPAS, Filipe; CAVALCANTE, Rita Laura Avelino; COELHO, Suzana Lanna Burnier. O professor e a pesquisa. Campinas, SP: Papirus, 2001.

MITJÁNS MARTÍNEZ, A. Criatividade no trabalho pedagógico e criatividade na aprendizagem: uma relação necessária? In: TACCA, M. C. V. R. (Org.) Aprendizagem e trabalho pedagógico. Campinas: Alínea, 2006, p. 69-94.

MITJÁNS MARTÍNEZ, A. O lugar da imaginação na aprendizagem escolar: suas implicações para o trabalho pedagógico. In: MARTÍNEZ, A.M.; ÁLVAREZ P. (Orgs.) O sujeito que aprende: diálogo entre a psicanálise e o enfoque histórico-cultural. Brasília: Liber Livro, 2014a, p. 63-97.

MITJÁNS MARTÍNEZ, A. Um dos desafios da Epistemologia Qualitativa: a criatividade do pesquisador. In: MITJÁNS MARTÍNEZ, A; NEUBERN, M.; MORI V. D. (Orgs.)

Subjetividade Contemporânea: discussões epistemológicas e metodológicas. Campinas: Alínea, 2014b, p. 61-86. 
NÓVOA, A. A formação tem que passar por aqui: as histórias de vida no Projeto Prosalus. In: NÓVOA, A.; FINGER, M. (Org.). O método (auto)biográfico e a formação. São Paulo: Paulus, 2010. p. 155-188.

PARENTE, A. G. L. Atividades investigativas no ensino de ciências. In: Pacto Nacional pela Alfabetização na Idade Certa. Interdisciplinaridade no ciclo de alfabetização (Caderno 08).

Brasília: MEC, SEB, 2015. Disponível em: https://sgmd.nute.ufsc.br/content/pnaicsgmd/caderno-8/aprofundando-o-tema-3.html Acesso em: 08 ago. 2020.

PARENTE, Andrela Garibaldi Loureiro; ALVES, José Moysés. A pesquisa da prática pedagógica em aulas de ciências por bolsistas do PIBID. Amaz RECM - Amazônia: Revista de Educação em Ciências e Matemática. v. 16, n. 36, p. 163-180, 2020. ISSN: 2317-5125. Disponível em: https:// periodicos.ufpa.br/index.php/revistaamazonia/article/view/8264/6330. Acesso em: 23 jul. 2020. Doi: http://dx.doi.org/10.18542/amazrecm.v16i36.8264.

PIETROCOLA, M. Curiosidade e imaginação - os caminhos do conhecimento nas ciências, nas artes e no ensino. In: CARVALHO, A. M. P. (Org.). Ensino de ciências: unindo a pesquisa e a prática. São Paulo: Pioneira Thomson Learning, 2004, p. 119-133.

ROMANELLI, Lilavate Izapovitz; JUSTI, Rosália da Silva. Aprendendo química. Ijuí: Ed. Unijuí, 1997.

STENHOUSE, Lawrence. La investigación como base de la enseñanza. Madri: Ediciones Morata, 1987.

TUNES, E.; VILLELA, M. C. T. R.; MITJÁNS MARTINEZ, A. Uma crítica as teorias clássicas da aprendizagem e à sua expressão no campo educativo. Linhas críticas, v. 12, n. 22, p. 109-130, jan/jun, 2006. ISSN 1516-4896. Disponível em: http://www.redalyc.org/artículo.oa?id=193517395007. Acesso em: 18 jun. 2019.

VIGOTSKI, Lev Semyonovich. Imaginação e criatividade na infância. Tradução Solange Affeche. São Paulo: Editora WMF Martins Fontes, 2014.

WOODS, P. Aspectos sociais da criatividade do professor. In: NÓVOA, A. (Org.). Profissão professor. Portugal: Porto Editora, 1991, p. 125-153.

Submetido em: 23 de abril de 2020 .

Aprovado em: 22 de julho de 2020. 